\title{
Why Optometrists Need to be Blogging
}

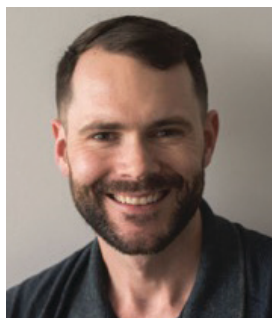

Cameron Martel

Cameron Martel is an experienced digital marketer, managing SEO and content campaigns since 2005. He currently works with dozens of eye care practices through his work with Marketing4ECPs. He's colourblind, but don't remind him, or he'll be seeing red (or so he thinks).Cam can be reached atwww.marketing4ecps.com or cameron@4ecps.com.

$\mathrm{W}$ e are huge proponents of blogging for Optometry practices. It has proven to be one of the most effective ways to generate new traffic, increase brand awareness, and attract new patients. That's why we have made it one of the pillars of our SEO (search engine optimization) strategy.

Blogging has fallen out of fashion, and those that do it often don't do it well. Many practices are focusing more on social media, leaving their blog rarely - if ever - updated. Let's explore why that's a missed opportunity for them, and a massive one for you.

\section{WHY BLOGGING IS ONE OF THE MOST POWERFUL ORGANIC MARKETING TOOLS AVAILABLE}

Google loves great content. It loves when its users find themselves down the deep-dive rabbit hole, exploring blog after blog and consuming copious amounts of information.

\section{Why?}

Because that means its users are finding value in the results Google shows, and if that's true, it means that those users will come back again and again. With more than $90 \%$ of the search market share, it stands to reason that their logic rings true.

It's also one of the least expensive ways to generate leads. If you create the blog yourself, all it costs is a small portion of your time. When done correctly, blogging can transform a business. Really.

\section{THE OPPORTUNITY BLOGGING REPRESENTS}

Those that scoff at blogging ignore two important points: first, that users want this information and actively seek it out; second, Google wants to serve this information from subject matter experts like you. In fact, in August of 2018, Google made a significant change to its algorithm that favours medical professionals for medically-focused keywords. In other words, when it comes to keywords surrounding eye care, Optometrists have a significant leg-up.

From a business point of view, blogging has four major benefits:

\section{Educate \& Qualify Future Patients \& Customers}

How many times have you had to defend the price of an eye exam or a pair of frames? The reality is that most people simply don't know what they don't know. Via your blog, you have a way to educate people about eye health, vision correction, eyewear, and what goes into them.

An educated patient is more likely to see your value and far less likely to shop based solely on price.

\section{Demonstrate Expertise \& Thought Leadership}

In an era of fake news and misinformation, people seek information from experts they can genuinely trust. If you can teach them about something they care about, you will earn their trust. 
The content you create for your blog can be easily shared on your social channels, including LinkedIn. By helping people answer their questions, you earn their trust and advocacy. That's powerful and not something you can accomplish via traditional advertising.

\section{Improved Rankings In \& Traffic From Google}

There is a lot of traffic out there. The keyword "how do colorblind glasses work" is searched more than 1,300 times per month in the United States and 150 times per month in Canada. Add in spin-offs (such as "do colorblind glasses work"), and those numbers climb significantly.

\section{Keyword Overview: how do colorblind glasses work

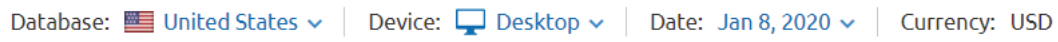

live update ORGANIC SEARCH

\begin{tabular}{lc}
\hline Volume & $1.3 \mathrm{~K}$ \\
\hline Number of results & $1.1 \mathrm{M}$
\end{tabular}

live update PAID SEARCH

\begin{tabular}{lr}
\hline $\mathrm{CPC}$ & $\$ 2.19$ \\
\hline Competition & 0.08
\end{tabular}

live update CPC DISTRIBUTION

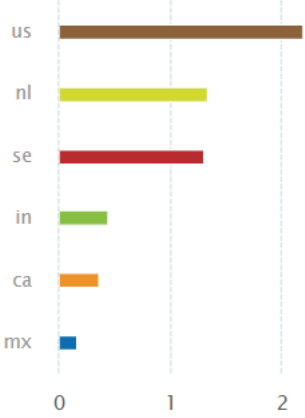

TREND

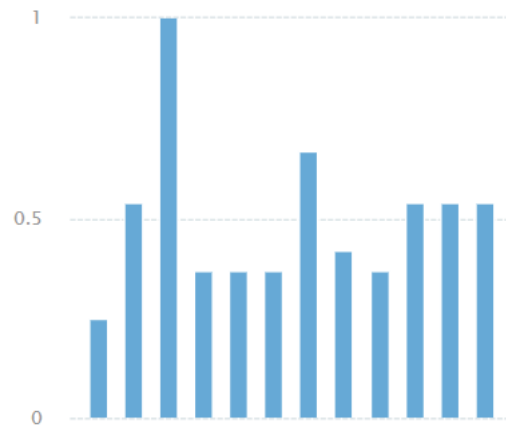

Go ahead and do a search for that keyword. Notice how two eye care practices appear? That could be you. After all, who better to answer that question than an optometrist?

What happens when you write an article that gets cited, references, and shared? The graph tends to look something like this:

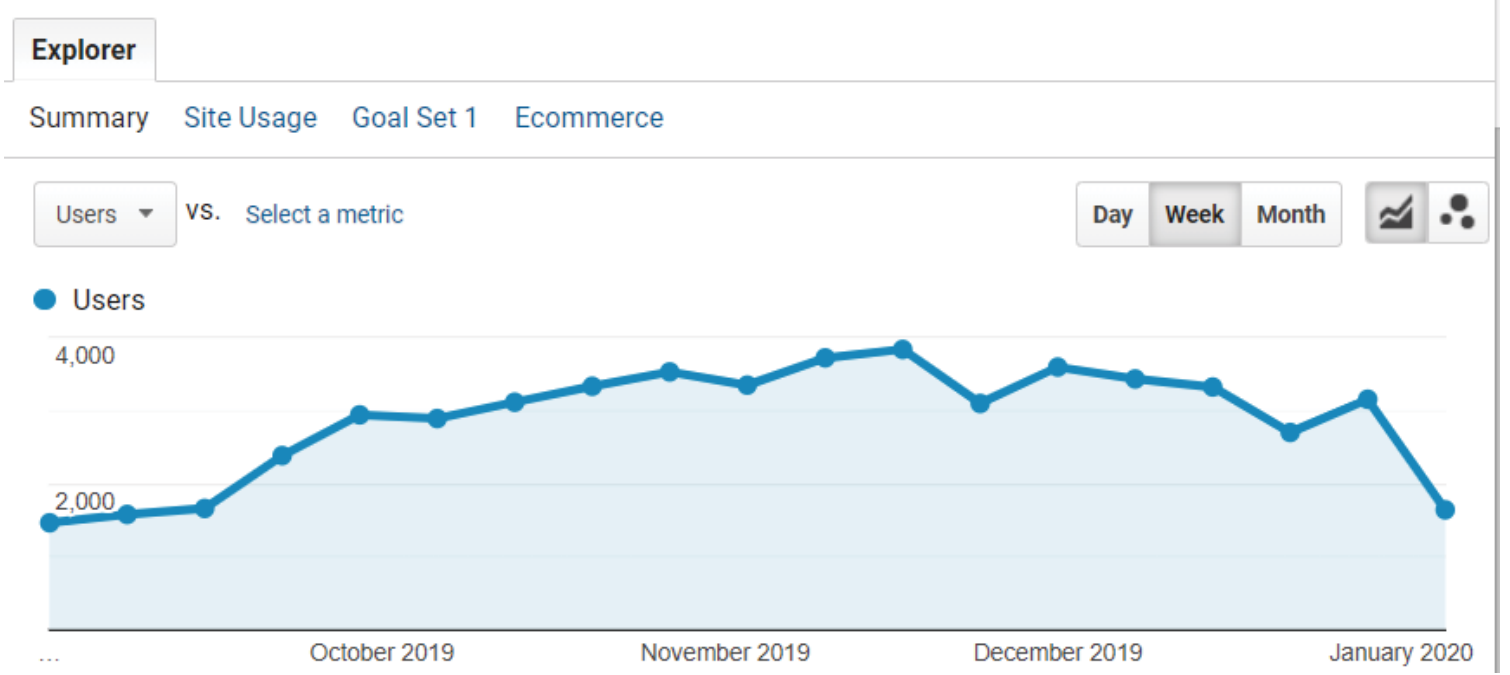


This Google Analytics screenshot showing weekly traffic was taken from an eye care practice in Maryland after the post went live in late September.

Note: This article was written in early January which is why January's numbers look so low by comparison.

\section{Generate Leads... Lots of Leads}

This is the most tangible (and important) benefit. Consider the graph from Google Analytics shown above: even if only $0.05 \%$ of the increased traffic resulted in a new patient or lead, for the above business, that means they are generating as many as 20 new leads per month, all from a single blog post.

How would that impact your business?

\section{INVEST IN YOUR BLOG \& REAP THE BENEFITS}

Blogging is a simple method that has a shallow learning curve. Invest in great content that is deep and rich in detail and then share it on your social channels. With consistency, you'll see your rankings climb and new customers walk through the front door. That is why you should be blogging. $\bullet$ 